\title{
Electrochemical Behavior of Passive Films Formed on the Surface of Coarse-, Fine- and Ultra-fine-Grained AA1050 Based on a Modified PDM
}

\author{
Seyed Omid Gashti ${ }^{1}$ Arash Fattah-alhosseini ${ }^{1} \cdot$ Yousef Mazaheri $^{1}$
}

Received: 4 February 2016/Revised: 7 April 2016/Published online: 18 May 2016

(C) The Chinese Society for Metals and Springer-Verlag Berlin Heidelberg 2016

\begin{abstract}
Electrochemical impedance spectroscopy (EIS) and Mott-Schottky analysis were carried out to evaluate the electrochemical behavior of the passive films formed on the surface of coarse-grained (CG), fine-grained (FG) and ultrafine-grained (UFG) $1050 \mathrm{Al}$ alloy (AA1050) samples in alkaline media ( $\mathrm{pH}$ value of 8.0) based on a modification of point defect model (PDM). The EIS results revealed that the polarization resistance increased from about $22.71-120.33 \mathrm{k} \Omega \mathrm{cm}^{2}$ for UFG sample when compared to CG sample (annealed sample). The semiconductor properties of the passive films formed on CG, FG and UFG AA1050 samples in the test solution were investigated by employing Mott-Schottky analysis in conjunction with PDM. The results indicated that donor densities were in the range of $2.19 \times 10^{21}-0.61 \times 10^{21} \mathrm{~cm}^{-3}$ and decreased with grain refinement. Finally, all electrochemical tests showed that the electrochemical behavior of AA1050 alloy was improved by decreasing the grain size, mainly due to the formation of thicker and less defective oxide films.
\end{abstract}

KEY WORDS: AA1050 alloy; Grain refinement; Ultra-fine grain (UFG); Passive film; Mott-Schottky

\section{Introduction}

In the last decade, a number of works have been studied about the electronic properties of surface passive film on non-ferrous metals, such as nickel [1, 2], chromium [3, 4], titanium [5, 6] and aluminum [7-9]. These investigations have given an important contribution to the better understanding of electrochemical behavior of these alloys. In the passive films, depending on the predominant present defects, either p- or n-type behaviors are observed. To characterize conductivity type (p- or n-type) and investigate the semiconducting properties of the passive films, the

Available online at http://link.springer.com/journal/40195

Seyed Omid Gashti

omid.gashti@gmail.com

1 Department of Materials Engineering, Bu-Ali Sina University, Hamedan 65178-38695, Iran
Mott-Schottky analysis has been found to be an effective method [10, 11].

In fact, mechanical and electrochemical behaviors of materials affected grain refinement due to increasing dislocation densities and fraction of high-angle grain boundaries $[12,13]$. UFG structures determined by a grain size of about 100-300 nm exhibited several noteworthy improvements in physical and mechanical properties of materials [14]. In the case of passive film formation, UFG structure changes the composition of the passive film and affects the semiconducting property of surface layer [15].

Aluminum and its alloys are widely used in industrial applications, especially in aluminum/air batteries because of their special properties such as low density, high strength-to-weight ratio, good appearance, high thermal conductivity and corrosion resistance [16, 17]. These materials exhibit a good corrosion behavior in atmosphere, weakly acidic and alkaline aqueous solutions due to the formation of native oxide film with a nanometric-scale thickness on their surfaces [18]. Reduction of the grain size 
and achieving UFG structure definitely change the corrosion behavior of aluminum and its alloys [19].

A limited number of works have reported that severe plastic deformation (SPD) techniques can either increase or decrease corrosion resistance of this group of materials [20-22]. Up to now, many studies focused on microstructural evaluations and mechanical properties of aluminum and its alloys that are produced by accumulative roll bonding (ARB) process as a SPD method [23-26]. However, the corrosion and passive behavior of these materials are yet to be studied and require more elaborate research. Recently, we have investigated the corrosion behavior of UFG 1050 aluminum alloy in a buffer borate solution [27]. Also, the effect of grain refinement on the passive behavior of UFG 1050 aluminum alloy in a borate buffer solution has been investigated in another study [28]. However, a comprehensive PDM is exploited here to elucidate the underlying mechanisms involved in the growth and breakdown of passive film in contrast to those mentioned before.

In this study, the first goal was to investigate the effect of grain refinement on dislocation density and hardness of AA1050 samples. For this purpose, the SPD method was successfully used for the grain refinement of AA1050 samples. The second goal of present work was to study the effect of grain refinement on the semiconducting behavior of passive films formed on AA1050 samples. For this purpose, the Mott-Schottky analysis of CG, FG and UFG AA1050 samples, in a solution with $\mathrm{pH}$ value of 8.0 in conjunction with PDM, was performed, and the concentration of defects was calculated as a function of grain refinement. The relationship between density of defects and grain size is discussed in order to understand the semiconducting behavior of AA1050. To the best of our knowledge, in the available literature, there are not any comprehensive studies on the modeling of the electrochemical behavior of UFG AA1050. Finally, the modeling of experimental data within PDM was presented.

\section{Experimental Procedure}

\subsection{Grain Refinement Process}

In this work, AA1050 sheet was used as a raw material and its chemical composition is presented in Table 1. All samples were first cut into strips of $150 \mathrm{~mm}$ length, $50 \mathrm{~mm}$

Table 1 Composition of AA1050 was used in this work (in wt\%)

\begin{tabular}{llllllll}
\hline $\mathrm{Fe}$ & $\mathrm{Si}$ & $\mathrm{Mg}$ & $\mathrm{Mn}$ & $\mathrm{Ti}$ & $\mathrm{V}$ & $\mathrm{Zn}$ & $\mathrm{Al}$ \\
\hline 0.35 & 0.04 & 0.02 & 0.01 & 0.01 & 0.01 & 0.01 & $\mathrm{Bal}$. \\
\hline
\end{tabular}

width and $1 \mathrm{~mm}$ thickness. Then, samples were annealed at $370{ }^{\circ} \mathrm{C}$ for $7200 \mathrm{~s}$. After that, two annealed strips were wire-brushed by stainless steel brush and degreased in acetone bath. Finally, the ARB process as a SPD technique was performed without lubrication, using a laboratory rolling mill with a loading capacity of 20 tons for two strips to be stacked over each other which were fastened by copper wires at the both ends of them. Strips were rolled to $50 \%$ reduction in thickness, and subsequently, the rollbonded strip was halved and stacked again after surface cleaning [26-28]. This procedure was repeated for up to 8 cycles. For all experimental measurements, three samples including annealed AA1050 as the CG sample, 4 cycles processed AA1050 as the FG sample, and 8 cycles processed AA1050 as the UFG sample were chosen.

\subsection{Characterization Evaluation}

The Vickers microhardness measurements were taken for hardness evaluation of samples. Measurements were obtained by using a BUEHLER microhardness measurement setup with a load of $0.98 \mathrm{~N}$ and indention time of $20 \mathrm{~s}$. The measurements were taken on the rolling direction (RD)-transverse direction (TD) plane of each sample, and the final values were determined as the average of ten measurements.

Microstructures were characterized using an optical microscopy (OM, Union Versamet-2) and a transmission electron microscopy (TEM, Philips-EM208S) operating at $100 \mathrm{kV}$. Microstructure of CG AA1050 (annealed) sample was obtained after grinding, polishing and etching with Keller's reagent $(1 \mathrm{~mL} 48 \% \mathrm{HF}, 1.5 \mathrm{~mL} \mathrm{HCl}$ and $10 \mathrm{~mL}$ $\mathrm{HNO}_{3}$ in $87.5 \mathrm{~mL}$ distilled water for $20 \mathrm{~s}$ ). TEM sample of UFG AA1050 ( 8 cycles) was prepared by utilizing a conventional jet electropolishing technique (Struers, Tenupol3, DK-2610) in a solution composed of 5 vol\% perchloric acid and $95 \mathrm{vol} \%$ ethyl alcohol at $-20{ }^{\circ} \mathrm{C}$. Also, selected area electron diffraction (SAED) pattern was taken.

\subsection{Electrochemical Tests}

The electrochemical measurements were taken in a conventional three-electrode flat cell of $250 \mathrm{~mL}$ volume under aerated conditions by using a $\mu$ AUTOLAB Type III/FRA2 system. The counter electrode was a Pt rod, and the reference electrode was $\mathrm{Ag} / \mathrm{AgCl}$ in $3.0 \mathrm{~mol} / \mathrm{L} \mathrm{KCl}$ solution. The working electrodes were involved in CG, FG and UFG AA1050 samples with an exposure area of $0.63 \mathrm{~cm}^{2}$. Prior to electrochemical measurements, each working electrode was mechanically polished with $\mathrm{SiC}$ abrasive paper up to 2000 grade and cleaned with deionized water. Then, each of them was immersed for $7200 \mathrm{~s}$ in an aqueous solution with $\mathrm{pH}$ value of $8\left(0.5 \mathrm{~mol} / \mathrm{L} \mathrm{H}_{3} \mathrm{BO}_{3}+0.1 \mathrm{~mol} / \mathrm{L} \mathrm{NaOH}\right)$ 
to form a steady-state passive film at room temperature. Potentiodynamic polarization curves were measured potentiodynamically at a scan rate of $1 \mathrm{mV} / \mathrm{s}$ starting from -0.8 to $1.0 V_{\mathrm{Ag} / \mathrm{AgCl}}$. EIS tests were performed at opencircuit potential (OCP) condition with a frequency range of $100 \mathrm{kHz}$ to $10 \mathrm{mHz}$ and an applied AC potential with an excitation signal of $10 \mathrm{mV}$. Moreover, each electrochemical measurement was repeated at least three times. The NOVA 1.7 impedance software was used for the EIS data modeling and curve-fitting method. Mott-Schottky analysis was performed on the passive films in the cathodic direction at a frequency of $1 \mathrm{kHz}$ using a $10 \mathrm{mV}$ AC signal and a step potential of $25 \mathrm{mV}$.

\section{Results and Discussions}

\subsection{Microstructural and Mechanical Characterization}

Microhardness variations of CG, FG and UFG AA1050 samples are illustrated in Fig. 1. As it can be seen, the hardness of the CG AA1050 is $33.6 \mathrm{HV}$ and a remarkable increase was achieved after applying SPD technique on annealed sample. In the UFG sample and after 8 cycles, hardness value reaches $63.3 \mathrm{HV}$ which is almost $88 \%$ greater than that of the CG sample. The rapid increase of FG sample hardness compared to CG sample is related to high rate of strain hardening as a result of high dislocation density. But with moving from FG sample to UFG sample, the hardness value slightly increased. This trend is in agreement with the previous research works [27, 28]. In fact, further grain refinement at larger strains did not lead to a higher hardness. In other words, the work- or strain-

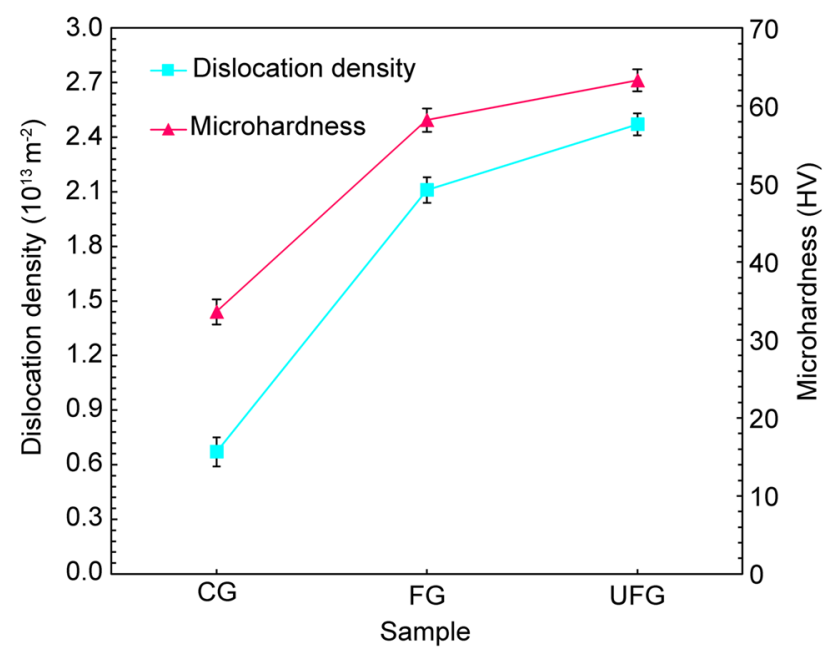

Fig. 1 Effect of grain refinement on dislocation density and hardness of AA1050 samples hardening behavior tends to show saturation at exceedingly large strains [29]. This phenomenon occurs when materials acquire a balanced density of dislocations. The balanced density of dislocations is ascribed to a dynamic balance between dislocations generation during the SPD method and their annihilation by the occurrence of dynamic restoration phenomena. Therefore, it can be concluded that both the reduction of grain size and dislocation density by dynamic recovery combine to keep the hardness almost constant for exceedingly high strains [23]. According to Ref. [30], the dislocation density $\left(\rho_{\mathrm{s}}\right)$ is related to hardness and it can be calculated by Eq. (1):

$\rho_{\mathrm{S}}=\frac{H_{\mathrm{V}}^{2}}{27 \alpha^{2} G^{2} b^{2}}-\frac{3 \sqrt{2} \sqrt{H_{\mathrm{V}}} \cot \varphi}{\sqrt{1.72} \pi^{2} b \sqrt{F}}$,

where $H_{\mathrm{V}}$ is the Vickers microhardness, $\varphi$ is Vickers indenter semi-angle (equal to $68^{\circ}$ ) [30,31], $\alpha$ is an empirical coefficient that is considered to be 0.3 in this work [30, 32], $G$ is the elastic shear modulus (26 GPa for aluminum), $b$ is the Burger's vector (equal to $0.286 \mathrm{~nm}$ for aluminum) [33], and $F$ is the applied force to the indenter. The dislocation densities which were calculated by hardness are plotted in Fig. 1. Values of dislocation density increased due to applying SPD method.

The optical micrograph of annealed sheet before applying any grain refinement process is illustrated in Fig. 2. It shows a homogeneous microstructure with an average grain size of $(35 \pm 2) \mu \mathrm{m}$. Figure 3 illustrates the TEM micrograph and the corresponding SAED pattern observed in RD-TD plane of the UFG AA1050 sample. As it can be seen, the average grain size of UFG sample has reached $(300 \pm 12) \mathrm{nm}$. The SAED patterns of these samples show ring-like patterns consisting of separate spots, which indicated that the area has large misorientation and a large number of grains with high-angle boundaries. During SPD method, the fraction of UFG regions

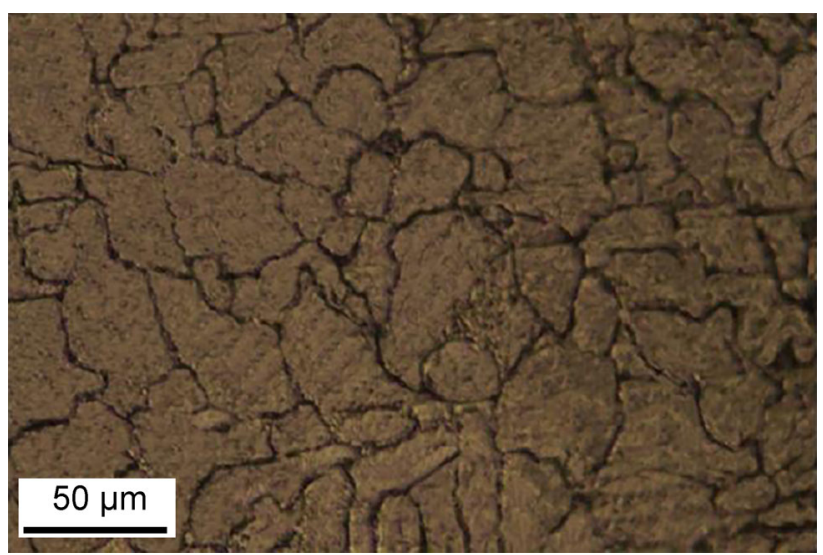

Fig. 2 Optical micrograph of annealed AA1050 before severe plastic deformation method 


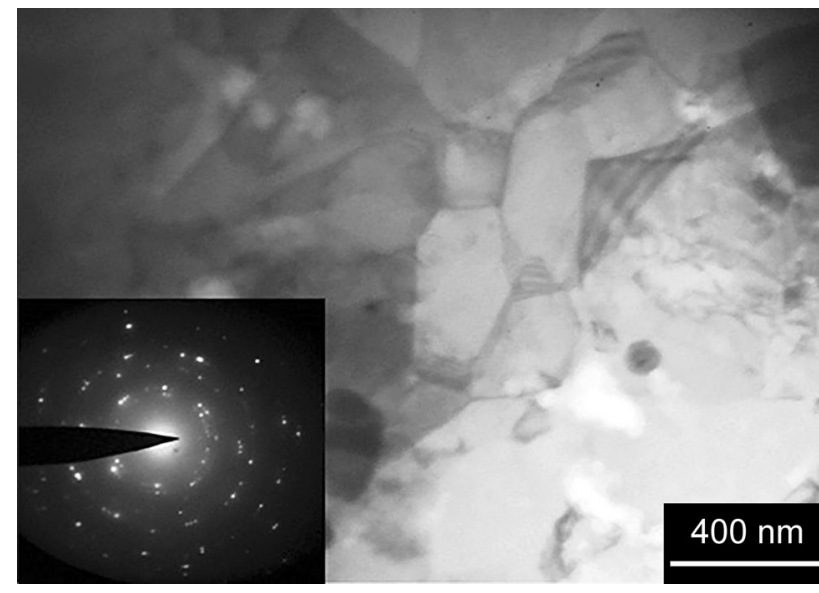

Fig. 3 TEM micrograph and corresponding SAED pattern of UFG AA1050 sample

increased and these grains were homogenously distributed due to increasing the number of ARB cycles or elevation of strain level [23].

\subsection{Open-Circuit Potential and Potentiodynamic Polarization Measurements}

The open-circuit potential (OCP) curves of CG, FG and UFG AA1050 samples in the solution with $0.5 \mathrm{~mol} / \mathrm{L} \mathrm{H}_{3}$ $\mathrm{BO}_{3}+0.1 \mathrm{~mol} / \mathrm{L} \mathrm{NaOH}(\mathrm{pH}$ value is 8$)$ are shown in Fig. $4 \mathrm{a}$. As it can be seen, after $1800 \mathrm{~s}$, the variation of potential with time is very slight and a complete stable condition was achieved after passing $7200 \mathrm{~s}$ to implement the subsequent electrochemical tests. All curves show similar trend of potential increase toward positive values. This behavior can be related to the continuous formation of passive film on the surface [34]. Moreover, compared to CG sample, higher OCP values for FG and UFG samples are related to the formation of much denser and protective passive films. Therefore, UFG sample has manifested the most positive OCP and had the highest corrosion resistance. These findings will be further corroborated in the course of the subsequent electrochemical analyses.

The potentiodynamic polarization curves of $\mathrm{CG}, \mathrm{FG}$ and UFG AA1050 samples are shown in Fig. 4b. All curves exhibit the same shapes, where the current varies linearly around the rest potential representing cathodic and anodic Tafel behavior. Also, the potentiodynamic polarization curves displayed that with increasing grain refinement, corrosion and passive current densities decreased and corrosion potential shifts to more positive values. The measured values of corrosion and passive current densities and corrosion potential of CG, FG and UFG AA1050 samples are reported in Table 2. Evidently, reduction of grain size has provided a better condition for the formation of passive films which are of higher protective behavior.

\subsection{EIS Measurements}

The Nyquist plots of CG, FG and UFG AA1050 samples in a solution with $0.5 \mathrm{~mol} / \mathrm{L} \mathrm{H}_{3} \mathrm{BO}_{3}+0.1 \mathrm{~mol} / \mathrm{L} \mathrm{NaOH}(\mathrm{pH}$ value of 8) are shown in Fig. 5a. One capacitive loop can be witnessed at all frequency regions which shows the existence of a single time constant that is related to the formation of a stable passive film on the surface of working electrode in this solution. The diameters of these loops are related to passive film resistance, directly. As it can be seen, with a reduction of grain size, diameters of these loops increase and display an increase in the passive film stability. Figure $5 \mathrm{~b}$ shows the Bode plots of CG, FG and UFG AA1050 samples in the test solution. Phase angle values are at maximum in intermediate frequencies. More importantly, all plots exhibit a resistive behavior in the high-frequency range, whereas a marked capacitive response can be witnessed in the middle- to low-frequency range.

The validity of the experimental EIS data can be checked by means of Kramers-Kronig transforms, which
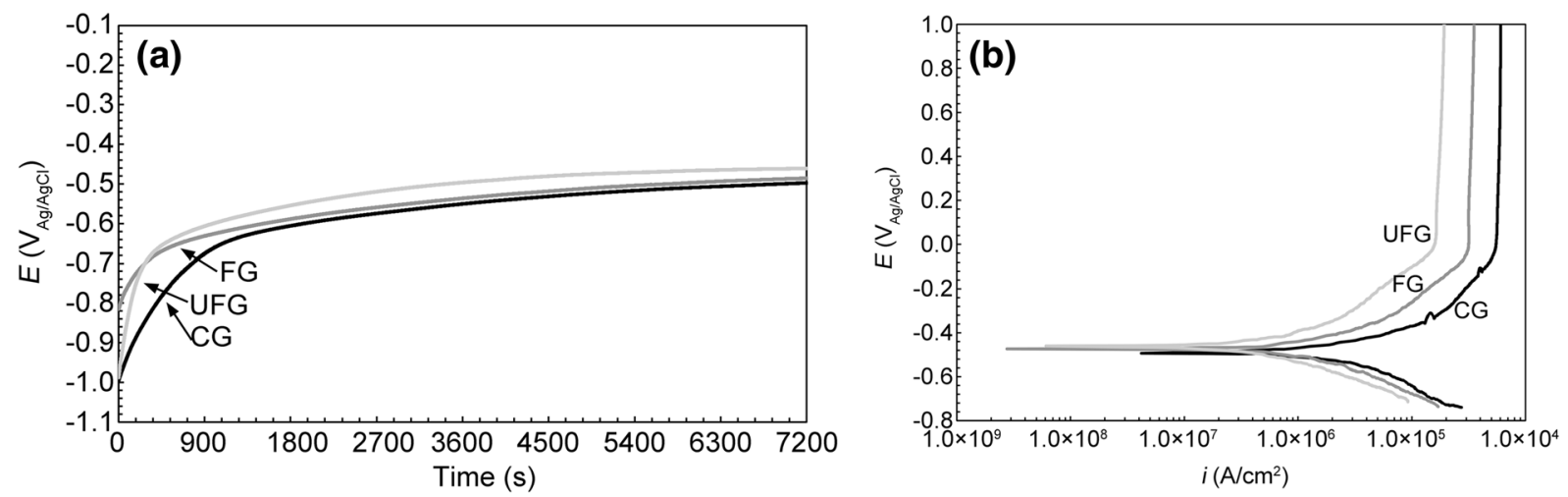

Fig. 4 Open-circuit potential a, potentiodynamic polarization b curves of CG, FG and UFG AA1050 samples in test solution (pH value of 8) 
Table 2 Calculated data of potentiodynamic polarization plots of CG, FG and UFG AA1050 samples in test solution

\begin{tabular}{llll}
\hline Sample & $E_{\text {corr }}\left(V_{\mathrm{Ag} / \mathrm{AgCl}}\right)$ & $i_{\text {corr }}\left(10^{-6} \mathrm{~A} \mathrm{~cm}^{-2}\right)$ & $i_{\text {pass }}\left(10^{-5} \mathrm{~A} \mathrm{~cm}^{-2}\right)$ \\
\hline CG & -0.493 & 2.0 & 6.5 \\
FG & -0.474 & 1.0 & 3.2 \\
UFG & -0.460 & 0.5 & 1.7 \\
\hline
\end{tabular}

are done by transforming the real axis into the imaginary axis and vice versa. More details about Kramers-Kronig transforms including accompanied formulations can be found elsewhere [34]. The comparison between the experimental impedance data and those obtained by means of the Kramers-Kronig transforms for CG, FG and UFG samples in test solution is shown in Fig. 6. As it can be seen, excellent agreement between the experimental and the corresponding Kramers-Kronig transform confirms the compliance of the system with the linear system theory.

The measured impedance data of all samples were simulated by using equivalent electrical circuit given in Fig. 7. In this equivalent circuit, $R_{\mathrm{S}}$ is solution resistance; $R_{\mathrm{P}}$ is passive film or polarization resistance; and CPE is constant phase element corresponding to the capacitance of passive film.

The obtained impedance parameters of $\mathrm{CG}, \mathrm{FG}$ and UFG samples in test solution are all illustrated in Table 3. It is observed that the polarization resistance of the UFG sample is higher than that of the CG and FG samples. Compared to the CG sample, the EIS results revealed that the polarization resistance increased from about 22.71$130.33 \mathrm{k} \Omega / \mathrm{cm}^{2}$ for UFG AA1050 sample. It is evident that the polarization resistance increases remarkably with reduction of grain size as an indication of corrosion resistance improvement. Considering the inverse relationship between the polarization resistance and the corrosion rate, a higher polarization resistance of a sample indicates its higher corrosion resistance. Also, Table 3 shows the values of the double-layer capacitance $\left(C_{\mathrm{dl}}\right)$ of $\mathrm{CG}, \mathrm{FG}$ and UFG samples in test solution. According to Fig. 9, for a circuit including a CPE, the double-layer capacitance can be calculated by [35]

$C_{\mathrm{dl}}=Y_{0}\left(\omega_{\max }\right)^{n-1}$,

where $Y_{0}$ is the CPE constant as admittance $\left(\Omega^{-1} \mathrm{~cm}^{-2} \mathrm{~s}^{n}\right)$, $\omega_{\max }$ is the angular frequency $(\mathrm{rad} / \mathrm{s})$ at which the imaginary part of the impedance has a maximum, and $n$ is a parameter related to surface roughness. As it is shown in Table 3, the double-layer capacitance decreased with increasing the number of ARB cycles and refining of grain size.

Generally, the passive film thickness $(d)$ can be determined by the Helmholtz model as [36]

$d=\frac{\varepsilon \varepsilon_{0} A}{C_{\mathrm{dl}}}$,

where $\varepsilon$ stands for the dielectric constant of the passive film (usually taken as 10 for aluminum and its alloys [37]), $\varepsilon_{0}$ denotes the vacuum permittivity $\left(8.854 \times 10^{-14} \mathrm{~F} / \mathrm{cm}\right)$, and $A$ is effective surface area. The inverse relationship between the double-layer capacitance and the passive film thickness implies the formation of thicker passive films considering the fact that the double-layer capacitance decreased due to grain refinement. This behavior indicates that grain refinement promotes the formation of thicker protective passive films.
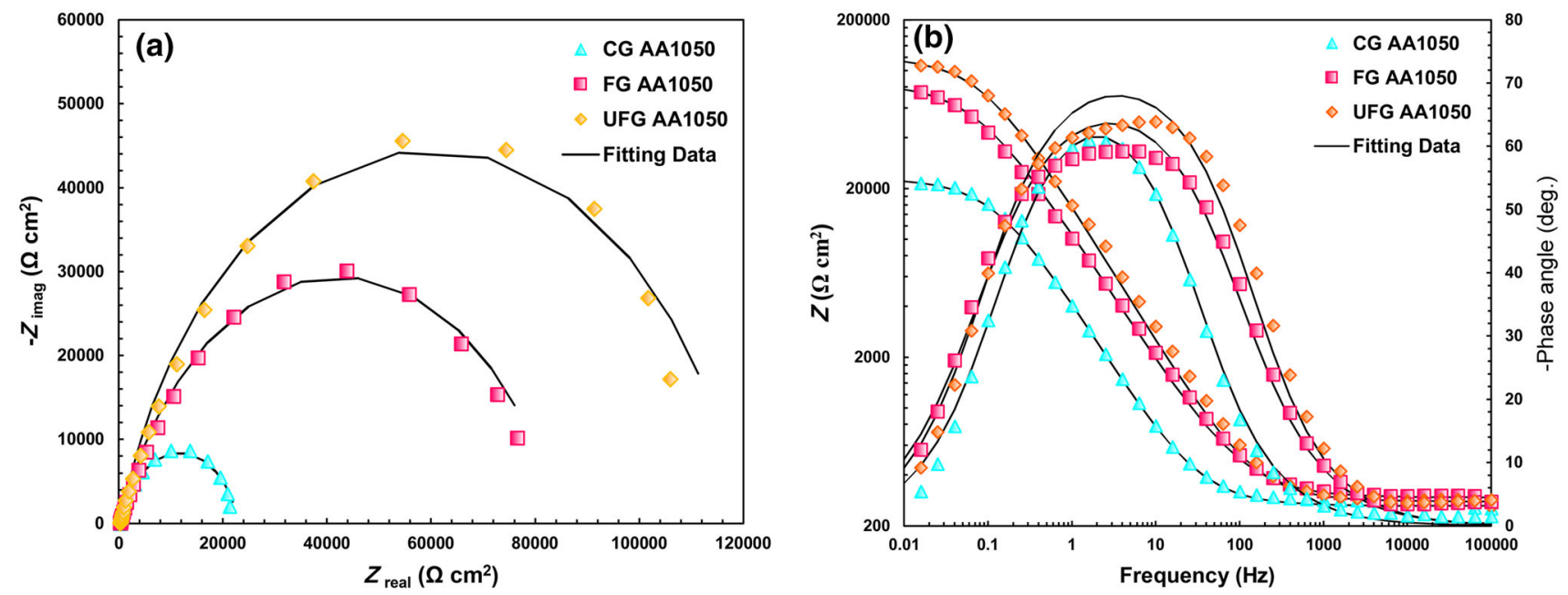

Fig. 5 Nyquist plots a, bode plots b of CG, FG and UFG AA1050 samples in test solution (pH value of 8) 

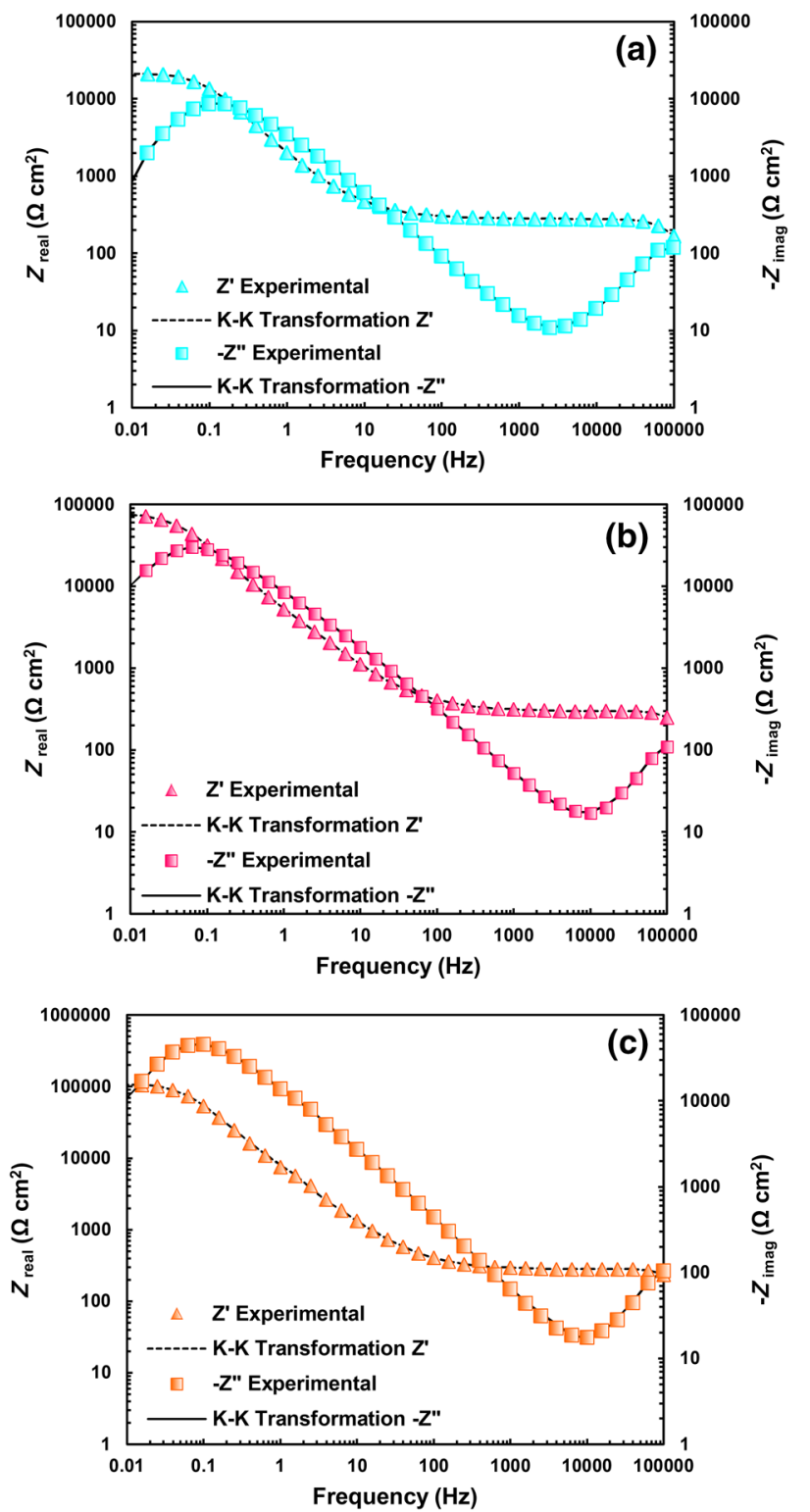

Fig. 6 Kramers-Kronig transformation of the EIS data obtained for CG a, FG b, UFG c AA1050 samples in test solution ( $\mathrm{pH}$ value of 8)

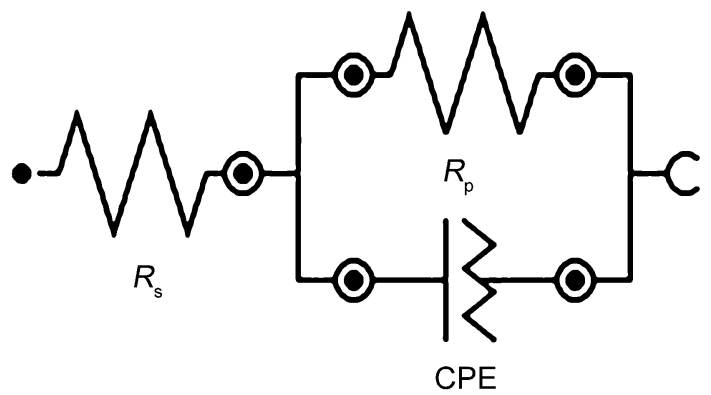

Fig. 7 Equivalent electrical circuit was proposed for modeling experimental EIS data
There are large fractions of non-equilibrium grain boundaries and high residual stresses in UFG sample. Moreover, inside the grains, dislocation density and microstrain are high. Thus, these are all assisting factors by which an accelerated growth of a thicker protective passive film associated with an enhanced corrosion resistance is expected [38]. Considering the EIS diagrams, it is clear that the shapes of the impedance plots are the same. Accordingly, corrosion mechanism was the same for all samples, but differences observed among them stem from their different microstructures.

\subsection{Mott-Schottky Analysis in Conjunction with PDM}

The Mott-Schottky plots of CG, FG and UFG AA1050 samples in the solution with $0.5 \mathrm{~mol} / \mathrm{L} \mathrm{H}_{3} \mathrm{BO}_{3}+0.1 \mathrm{~mol} /$ $\mathrm{L} \mathrm{NaOH}$ (pH value of 8) are illustrated in Fig. 8. In each plot, there is a region in which $1 / C^{2}$ and $E$ possess a nearlinear relationship. The positive slope in this region is correlated with an n-type semiconducting behavior. The donor density $\left(N_{\mathrm{D}}\right)$ of each sample was calculated from these positive slopes [34-38]:

$\frac{1}{C^{2}}=\frac{2}{\varepsilon \varepsilon_{0} e N_{\mathrm{D}}}\left(E-E_{\mathrm{fb}}-\frac{k_{\mathrm{B}} T}{e}\right)$,

where $e$ is the electron charge and $k, T$ and $E_{\mathrm{fb}}$ are the Boltzmann constant, absolute temperature and flat band potential, respectively. The defect structure of the passive film formed on $\mathrm{Al}$ can be envisioned as series of defects generation and annihilation reactions occurring at the metal/passive film interface and at the passive film/solution interface, as depicted in Fig. 9 (modified PDM). As it can be seen from Fig. 8, the Mott-Schottky plots of CG, FG and UFG AA1050 samples in the solution with $0.5 \mathrm{~mol} / \mathrm{L}$ $\mathrm{H}_{3} \mathrm{BO}_{3}+0.1 \mathrm{~mol} / \mathrm{L} \mathrm{NaOH}$ solution ( $\mathrm{pH}$ value of 8.0) only show the n-type behavior. Therefore, according to the PDM [36], the flux of oxygen vacancies and/or cation interstitials $\left(\mathrm{Al}^{3+}\right)$ through the passive film is essential to the film growth process.

Considering a recently modified PDM which propounds incorporation of hydroxyl vacancies alongside other defects, the flux of oxygen vacancies and/or hydroxyl vacancies and/or cation interstitials through the passive film is essential to the film growth process [39-41]. It has been suggested that the formation of point defects are under the influence of solution $\mathrm{pH}$ and it can be related to hydration-dehydration processes occurring at the passive film/solution and metal/passive film interfaces, respectively. Moreover, it has been postulated that the hydration and diffusion of hydroxyl vacancies are favored depending on the alkalinity of the solution [39-41]. In this manner, the 
Table 3 Variations in the impedance parameters of CG, FG and UFG samples

\begin{tabular}{|c|c|c|c|c|c|c|}
\hline \multirow[t]{2}{*}{ Parameter } & \multicolumn{2}{|c|}{ CG sample } & \multicolumn{2}{|c|}{ FG sample } & \multicolumn{2}{|c|}{ UFG sample } \\
\hline & Value & Estimated error & Value & Estimated error & Value & Estimated error \\
\hline$R_{\mathrm{s}}\left(\Omega \mathrm{cm}^{2}\right)$ & 262 & 1.113 & 286 & 2.112 & 270 & 2.095 \\
\hline$R_{\mathrm{p}}\left(\mathrm{k} \Omega \mathrm{cm}^{2}\right)$ & 22.71 & 1.562 & 86.94 & 2.801 & 120.33 & 2.712 \\
\hline$Y_{0}\left(\mu \Omega^{-1} \mathrm{~s}^{n} \mathrm{~cm}^{-2}\right)$ & 53.01 & 1.607 & 23.65 & 1.955 & 13.44 & 2.225 \\
\hline$C_{\mathrm{dl}}\left(\mu \mathrm{F} \mathrm{cm}{ }^{-2}\right)$ & 57.90 & 1.607 & 29.98 & 1.955 & 14.84 & 2.225 \\
\hline$n$ & 0.810 & 0.597 & 0.744 & 0.693 & 0.786 & 0.678 \\
\hline$\chi^{2}$ & 0.023 & - & 0.047 & - & 0.065 & - \\
\hline
\end{tabular}

relative dominance of kinetics of Reactions $3 a$ and $3 b$ with respect to the kinetics of Reaction 7, which are presented in Fig. 9, may be responsible for the observed thickening.

However, cation vacancies are electron acceptors and cannot be responsible for the n-type electronic character of the passive film. Thus, we are forced to conclude that the dominant defects in the passive film are the oxygen vacancies which are electron donors, and thereby, the passive film is $n$-type doped as it is observed in MottSchottky analysis. In this modified PDM, the generation of oxygen vacancies at the $\mathrm{Al} / \mathrm{Al}_{2} \mathrm{O}_{3}$ interface (Reactions $3 \mathrm{a}$ and $3 b$ in Fig. 9) and the flux of $\mathrm{O}^{2-}$ vacancies through the passive film, resulting from barrier layer dissolution, are essential for the film growth process.

Table 4 shows the calculated donor density of $\mathrm{CG}, \mathrm{FG}$ and UFG AA1050 samples in $0.5 \mathrm{~mol} / \mathrm{L} \mathrm{H}_{3} \mathrm{BO}_{3}+0.1$ $\mathrm{mol} / \mathrm{L} \mathrm{NaOH}$ solution ( $\mathrm{pH}$ value of 8 ). The donor densities are around $10^{21} \mathrm{~cm}^{-3}$, which are comparable to those reported in other studies [27, 28]. These high values of the donor density can be correlated with a higher density of oxygen vacancies in the passive film. These results show that the donor density, which is affected by grain size, decreased due to the grain refinement. It is observed that the calculated donor density dropped from $2.19 \times 10^{21}$ to $0.61 \times 10^{21} \mathrm{~cm}^{-3}$ when the CG structure was transformed to UFG structure under the influence of ARB process. On the other hand, lower $N_{\mathrm{D}}$ values can be correlated with the lower conductivity of passive film [42]. Due to direct relationship between conductivity and current density, a decrease in the conductivity of passive film led to the reduction of passive current density. Therefore, the grain refinement has led to the reduction of both donor and passive current densities simultaneously. These results are in agreement with the data in Table 2.

Therefore, passive films will be denser for UFG sample when compared to annealed sample which is a direct consequence of the grain refinement process. Finally, it can be concluded that electrochemical behavior of AA1050 was improved to a large extent under the influence of grain refinement, mainly due to the formation of a thicker and less defective oxide film.
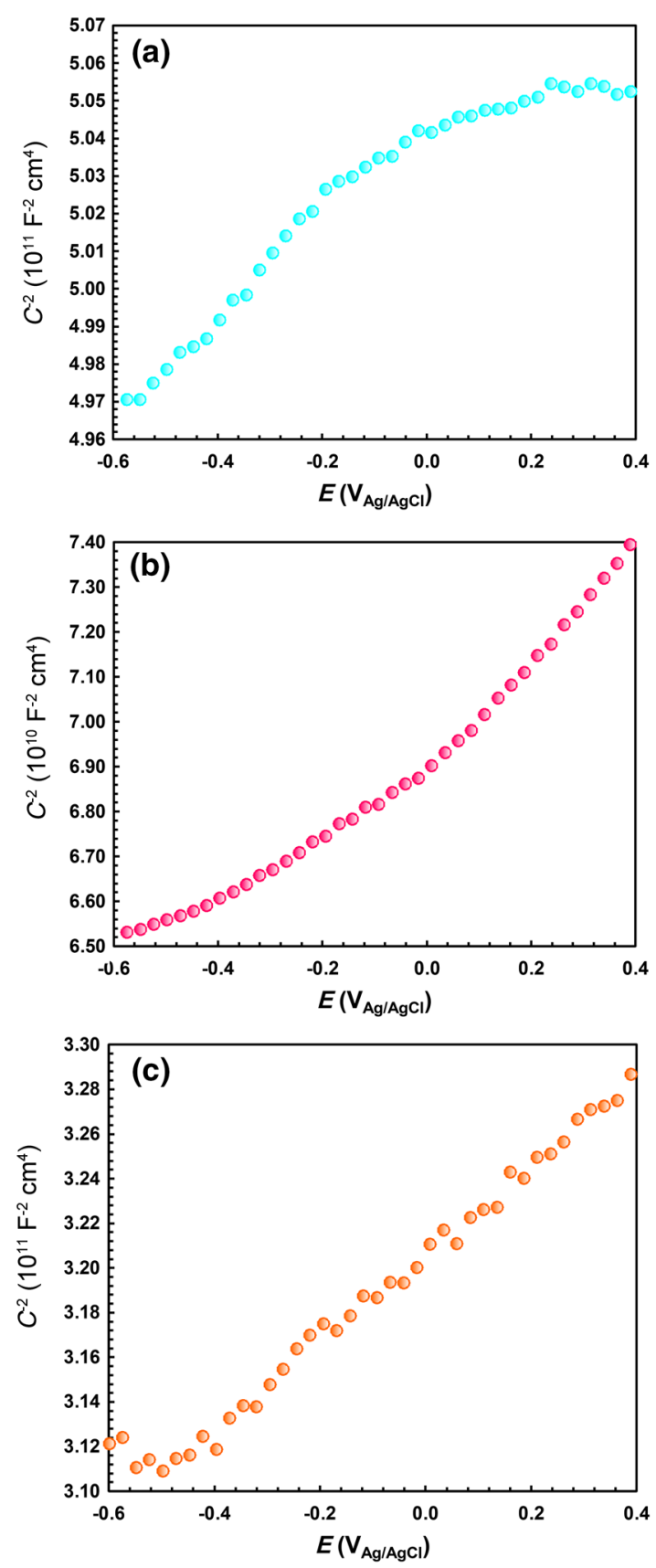

Fig. 8 Mott-Schottky plots of CG a, FG b, UFG c AA1050 samples in test solution ( $\mathrm{pH}$ value of 8 ) 


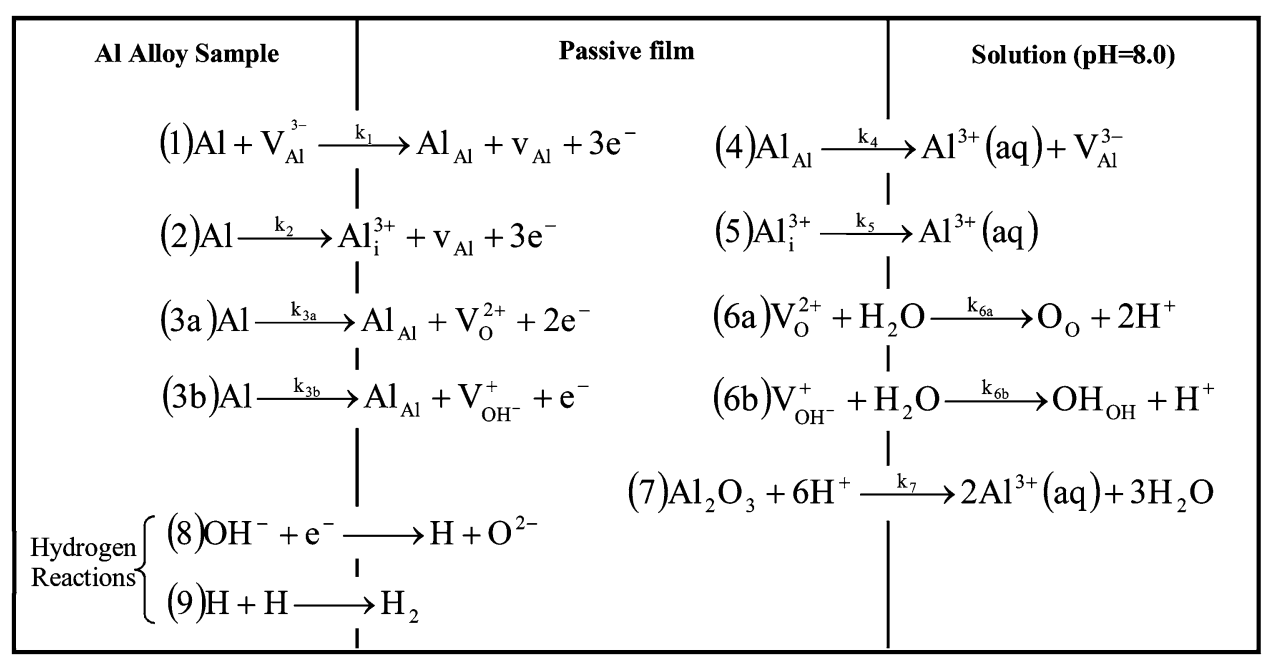

Fig. 9 Modified PDM for passivation of AA1050 in test solution ( $\mathrm{pH}$ value of 8.0), where $V_{\mathrm{Al}}^{3-}$ is aluminum vacancy on the aluminum sublattice of the passive film, $\mathrm{Al}_{i}^{3+}$ is interstitial aluminum, $\mathrm{Al}_{\mathrm{Al}}$ is aluminum cation on the aluminum sublattice of the passive film, $V_{\mathrm{O}}^{2+}$ is oxygen vacancy on the oxygen sublattice of the passive film, $\mathrm{O}_{\mathrm{O}}$ is oxygen anion on the oxygen sublattice of the passive film, $\mathrm{Al}^{3+}(\mathrm{aq})$ is aluminum cation in solution

Table 4 Variations of the donor density $\left[N_{\mathrm{D}}\left(10^{21} \mathrm{~cm}^{-3}\right)\right]$ of CG, FG and UFG AA1050 samples extracted from Mott-Schottky plots slopes

\begin{tabular}{lcc}
\hline CG sample & FG sample & UFG sample \\
\hline $2.19 \pm 0.3$ & $1.29 \pm 0.2$ & $0.61 \pm 0.2$
\end{tabular}

\section{Conclusions}

1. The SPD method was successful for grain refinement. The microstructural evaluations showed that the mean grain size decreased from $(35 \pm 2) \mu \mathrm{m}$ for the annealed sample (CG) to $(300 \pm 12) \mathrm{nm}$ for the UFG structure.

2. Microhardness tests showed that with a reduction of grain size, the microhardness value and dislocation density increased.

3. Potentiodynamic polarization and EIS results showed that passive behavior of the FG and UFG samples was enhanced when compared to the CG sample. This improving effect was expected to become more pronounced as the grain size decreased.

4. Mott-Schottky analysis indicated that the passive films behaved as n-type semiconductors and grain refinement did not change the semiconductor type of the passive films. This analysis showed that the calculated donor density dropped from $2.19 \times 10^{21}$ to $0.61 \times 10^{21} \mathrm{~cm}^{-3}$ after the grain refinement and obtaining the final UFG structure.

\section{References}

[1] Z. Grubač, Ž. Petrović, J. Katić, M. Metikoš-Huković, R. Babić, J. Electroanal. Chem. 645, 87 (2010)

[2] K. Darowicki, S. Krakowiak, P. Ślepski, Electrochim. Acta 51, 2204 (2006)

[3] J.S. Kim, E.A. Cho, H.S. Kwon, Electrochim. Acta 47, 415 (2001)

[4] D.-S. Kong, S.-H. Chen, C. Wang, W. Yang, Corros. Sci. 45, 747 (2003)

[5] A.M. Schmidt, D.S. Azambuja, E.M.A. Martini, Corros. Sci. 48, 2901 (2006)

[6] K. Azumi, M. Seo, Corros. Sci. 43, 533 (2001)

[7] F.J. Martin, G.T. Cheek, W.E.O. Grady, P.M. Natishan, Corros. Sci. 47, 3187 (2005)

[8] K.L. Levine, D.E. Tallman, G.P. Bierwagen, J. Mater. Process. Technol. 199, 321 (2008)

[9] B. Zhang, Y. Li, F. Wang, Corros. Sci. 52, 2612 (2010)

[10] E. Sikora, D.D. Macdonald, Solid State Ionics 49, 141 (1997)

[11] J. Sikora, E. Sikora, D.D. Macdonald, Electrochim. Acta 45, 1875 (2000)

[12] A.A. Khamei, K. Dehghani, Acta Metall. Sin. (Engl. Lett.) 28, 322 (2015)

[13] A. Fattah-alhosseini, O. Imantalab, J. Alloys Compd. 632, 48 (2015)

[14] A.V. Syugaev, E.A. Pechina, N.V. Lyalina, S.F. Lomaeva, M.V. Mar'in, S.M. Reshetnikov, Protec. Met. Phys. Chem. Surf. 50, 841 (2014)

[15] L. Liu, Y. Li, F. Wang, J. Mater. Sci. Technol. 26, 1 (2010)

[16] Y. Liu, Y.F. Cheng, J. Appl. Electrochem. 41, 151 (2011)

[17] Z. Ye, D. Liu, C. Li, X. Zhang, Z. Yang, M. Lei, Acta Metall. Sin. (Engl. Lett.) 27, 705 (2014)

[18] B. Zhang, Y. Li, F. Wang, Corros. Sci. 49, 2071 (2007)

[19] E. Akiyama, Z. Zhang, Y. Watanabe, K. Tsuzaki, J. Solid State Electrochem. 13, 277 (2009)

[20] M.F. Naeini, M.H. Shariat, M. Eizadjou, J. Alloys Compd. 509, $4696(2011)$

[21] M.K. Chung, Y.S. Choi, J.G. Kim, Y.M. Kim, J.C. Lee, Mater. Sci. Eng., A 366, 282 (2004) 
[22] W. Wei, K.X. Wei, Q.B. Du, Mater. Sci. Eng., A 454-455, 536 (2007)

[23] M. Eizadjou, H. Danesh Manesh, K. Janghorban, J. Alloys Compd. 474, 406 (2009)

[24] H. Pirgazi, A. Akbarzadeh, R. Petrov, L. Kestens, Mater. Sci. Eng., A 497, 132 (2008)

[25] L. Su, C. Lu, H. Li, G. Deng, K. Tieu, Mater. Sci. Eng., A 614, 148 (2014)

[26] S.O. Gashti, A. Fattah-alhosseini, Y. Mazaheri, M.K. Keshavarz, J. Alloys Compd. 658, 854 (2016)

[27] A. Fattah-alhosseini, S.O. Gashti, J. Mater. Eng. Perform. 24, 3386 (2015)

[28] A. Fattah-alhosseini, S.O. Gashti, Acta Metall. Sin. (Engl. Lett.) 28, 1222 (2015)

[29] A. Shabani, M.R. Toroghinejad, A. Shafyei, Mater. Des. 40, 212 (2012)

[30] A. Nazari, J. Aghazadeh Mohandesi, S. Tavareh, Comput. Mater. Sci. 50, 1781 (2011)

[31] S. Graça, R. Colaço, P.A. Carvalho, R. Vilar, Mater. Lett. 62, 3812 (2008)
[32] M. Chen, E. Ma, K.J. Hemker, H. Sheng, Y. Wang, X. Cheng, Science 300, 1275 (2003)

[33] J.L. Lv, H.Y. Luo, Surf. Coat. Technol. 235, 513 (2013)

[34] E. Van Gheem, J. Vereecken, C. Le Pen, J. Appl. Electrochem. 32, 1193 (2002)

[35] C.H. Hsu, F. Mansfeld, Corrosion 57, 747 (2001)

[36] D.D. Macdonald, J. Electrochem. Soc. 153, B213 (2006)

[37] S.O. Gashti, A. Fattah-alhosseini, Anal. Bioanal. Electrochem. 6, 535 (2014)

[38] J.J. Gray, C.A. Orme, Electrochim. Acta 52, 2370 (2007)

[39] R. Cabrera-Sierra, J. Vazquez-Arenas, S. Cardoso, R.M. LunaSánchez, M.A. Trejo, J. Marín-Cruz, J.M. Hallen, Electrochim. Acta 56, 8040 (2011)

[40] R. Cabrera-Sierra, J.M. Hallen, J. Vazquez-Arenas, G. Vázquez, I. González, J. Electroanal. Chem. 638, 51 (2010)

[41] P. Acevedo-Peña, J. Vázquez-Arenas, R. Cabrera-Sierra, L. Lartundo-Rojas, I. González, ECS Trans. 50, 21 (2013)

[42] J. Zhang, W. Zhang, C. Yan, K. Du, F. Wang, Electrochim. Acta 55, 560 (2009) 